Euskal ikerketen aldizkaria | Revue d'études basques |

Revista de estudios vascos | Basque studies review

$4 \mid 1999$

Numéro IV

\title{
Hommage au Professeur Jean Haritschelhar
}

Jean-Baptiste Orpustan

\section{OpenEdition \\ Journals}

Édition électronique

URL : http://journals.openedition.org/lapurdum/1524

DOI : 10.4000/lapurdum.1524

ISSN : 1965-0655

Éditeur

IKER

Édition imprimée

Date de publication : 1 octobre 1999

Pagination : 7-8

ISBN : 2-84127-156-0

ISSN : $1273-3830$

Référence électronique

Jean-Baptiste Orpustan, « Hommage au Professeur Jean Haritschelhar », Lapurdum [En ligne], 4 |

1999, mis en ligne le 01 avril 2010, consulté le 31 janvier 2020. URL : http://journals.openedition.org/ lapurdum/1524; DOI : 10.4000/lapurdum.1524 
Jean-Baptiste ORPUSTAN

\section{HOMMAGE AU PROFESSEUR JEAN HARITSCHELHAR}

\section{Préface et dédicace}

Lapurdum, revue annuelle de l'Unité Mixte de Recherches de Bordeaux III et de l'UPPA “Centre de recherches sur la langue basque et les textes basques" et du Département Interuniversitaire d'Études Basques de Bayonne, avec ce quatrième numéro d'octobre 1999 rend hommage à celui qui créa, voici déjà une vingtaine d'années, les études universitaires basques à Bayonne (1979) puis l'Unité de recherches d'Études Basques de Bordeaux III associée au CNRS (1983) que continue l'UMR actuelle : le professeur Jean Haritschelhar.

Chacun de ceux qui publient ici un de leurs travaux de recherche a une dette envers lui, plusieurs d'entre nous comme directeur de leur thèse, d'autres pour avoir travaillé avec lui comme lecteurs à l'Université de Bordeaux III, d'autres encore pour avoir suivi ses cours de basque, que, comme successeur de René Lafon à la chaire de basque (du temps que les chaires nommaient assez "mandarinalement" ce que nous appelons, plus discrètement en apparence, des "postes"!), il était le seul à dispenser en basque, d'autres encore et même la plupart pour s'être vus généreusement ouvrir les pages du Bulletin du Musée Basque dont il fit un temps, comme directeur attentif à la qualité des publications, la "revue des études et recherches basques" seule revue basque de France alors où les recherches universitaires sur la langue et la littérature basques, sujets privilégiés de notre Lapurdum, qui accorde aussi une place aux sciences humaines et sociales dans un but avoué et scientifiquement bénéfique d'interdisciplinarité, pouvaient prendre place.

Bien d'autres auteurs, et même illustres, auraient pu prétendre à participer à un hommage à l'action de Jean Haritschelhar, et tout d'abord l'ensemble de ses collègues de l'Euskaltzaindia "Académie de la Langue Basque" qu'il a le grand honneur de présider, pour la première fois comme universitaire français et comme Français tout court. Ils n'y manqueront sûrement pas, et dans des conditions et des occasions plus solennelles et spectaculaires que ne saurait assumer à elle seule notre revue bayonnaise vouée à la seule recherche universitaire. Ce Lapurdum IV s'adresse avant tout au professeur émérite de langue et littérature basques de Bordeaux III, joignant les noms de ses rédacteurs habituels à ceux qui, en Pays basque de France ou d'Espagne, ont participé aux travaux de recherche et d'enseignement de Jean Haritschelhar. Quelques autres sans doute, qui auraient aimé y prendre part, manqueront pour telle ou telle circonstance particulière; l'équipe de Lapurdum les associe en pensée au présent hommage.

"Monsieur le Professeur, en mettant en place les enseignements universitaires de basque à Bayonne, même si l'habilitation des diplômes dits "nationaux" prit un certain temps - et ce ne fut pas, comme dit un de nos auteurs à une autre occa- 
sion, "çure faltaz edo çu hartaco ez gai içanez", "par votre faute et parce vous n'étiez pas propre à cela", mais parce que l'esprit des hommes - et des femmes aussi - qui tenaient alors la clé des décisions n'était pas encore mûr... -, en créant l'unité de recherches associée, vous avez donné le coup d'envoi pour tout ce qui a suivi, et dans ce suivi, il y a justement aussi Lapurdum et spécialement ce Lapurdum quartum. En notre nom à tous, il vouss est dédié."

\author{
ESKAINTZA \\ Jean Haritschelhar jaunari, \\ Norbaitek noizpait norbaiti \\ Eskaintzea bere lanen, \\ Jauna, zuzen baldin bazen, \\ Guk egitea zen zuri. \\ Nork ikertu, nork ikasi, \\ Hemen izenpetzen duten \\ Ainitzek zor zautzuten \\ Zurekin baitziren hasi ; \\ Batzuek zure laguntzaz \\ Behin ez egonik eskas. \\ Lehen urratsak emanik, \\ Gure LAPURDUM herena \\ Agertua zen jadanik: \\ Datorzula laugarrena.
}

1999-ko uztailaren 29-a

\title{
DÉDICACE :
}

"S'il était juste que tel jour

quelqu'un dédiât ses travaux

à quelqu'un, c'était, Monsieur,

que nous vous le fissions à vous.

Qui pour chercher, qui pour savoir,

la plupart de ces signataires

se devaient de rendre leur dû

d'avoir, sous vous, fait leur débuts;

et beaucoup pour n'être jamais

restés en manque de votre aide.

Assuré de ses premiers pas,

notre Lapurdum troisième

déjà sorti, que vous revienne

ce quatrième numéro."

Le 29 juillet 1999

Jean-Baptiste ORPUSTAN

Professeur de langue et littérature basques

à l'Université de Bordeaux III

UMR 5478 